\title{
TRAÇADORES: O USO DE AGENTES QUÍMICOS PARA ESTUDOS HIDROLÓGICOS, AMBIENTAIS, PETROQUÍMICOS E BIOLÓGICOS
}

\author{
Láuris Lucia da Silva, Claudio Luis Donnici* e José Danilo Ayala \\ Departamento de Química, Universidade Federal de Minas Gerais, Av. Antônio Carlos, 6627, \\ 31270-901 Belo Horizonte - MG, Brasil \\ Cíntia Helena de Freitas, Rubens Martins Moreira e Amenônia Maria Ferreira Pinto \\ Centro de Desenvolvimento da Tecnologia Nuclear, Av. Prof. Mario Werneck,s/n, Cidade Universitária, \\ 31270-901 Belo Horizonte - MG, Brasil
}

Recebido em 7/7/08; aceito em 30/1/09; publicado na web em 3/7/09

\begin{abstract}
TRACERS: THE USE OF CHEMICAL AGENTS FOR HYDROLOGICAL, ENVIRONMENTAL, PETROCHEMICAL AND BIOLOGICAL STUDIES. This paper presents a revision of the history, definitions, and classification of tracers (natural and artificial, internal and external). The fundamental ideas concerning tracers are described, followed by their application illustrated by typical examples. The advantages and disadvantages of five classes among the most frequently used external tracers (fluorescent, microbial, chemical, radioactive and activable isotopes) are also described in detail. This review also presents some interesting and modern applications of tracers in the areas of diagnostics in medical practice, environmental pollution, hydrology and petroleum chemistry.
\end{abstract}

Keywords: tracers; definitions and classifications; technological applications.

\section{INTRODUÇÃO: HISTÓRICO E DEFINIÇÕES}

O conhecimento, mapeamento quantitativo e monitoramento das fontes de água doce do nosso planeta são importantíssimos, pois a água é fundamental para a vida na Terra. ${ }^{1}$ Assim, na área de hidrologia, com o interesse vital e necessário do uso de agentes que pudessem monitorar os fluxos de água, surgiram os traçadores, que são usados tanto a nível superficial quanto a nível subterrâneo. Com estes agentes incorporados aos fluxos aquáticos têm-se metodologias diretas, geralmente rápidas e comumente únicas, das quais se pode obter a determinação de fontes originais de água, ou a comprovação de novos afluentes aquáticos, delineamento de velocidades de fluxo de água e até a identificação de fontes poluentes. Cabe ressaltar que, na verdade, o primeiro relato histórico do uso de traçadores ocorreu em 20 d.C. quando o tetrarca Herodes Antipas utilizou cascas moídas para identificação das fontes do Rio Jordão. ${ }^{2}$

Desta feita, a partir do uso específico para monitoramento de veios aquáticos, surgiu o agente dito como traçador, que tem hoje grande aplicabilidade em diferentes áreas científicas e tecnológicas. Podese, então, definir traçador como uma espécie (química ou biológica) que serve para "marcar" uma fase específica ou parte de um sistema. ${ }^{3}$ Mais especificamente, traçador é qualquer substância, ou partícula/ entidade (química ou biológica), que pode ser usada para seguir, quer pontualmente ou de forma contínua, o comportamento de um determinado sistema ou de um componente, tal como volume de água, quer em ambiente aberto (hidrologia de superfície) ou subterrâneo (ambiente poroso ou fissurado). ${ }^{3}$ Cabe esclarecer que muitas vezes as definições traçador e marcador (tracer e marker, respectivamente) são confundidas entre si; contudo, cabe esclarecer as suas diferenças importantes. Do ponto de vista semântico podem-se ter significados similares para ambos os termos; contudo, do ponto de vista científico há conotações diferentes, a saber: usa-se o termo marcador quando se obtêm informações extrínsecas dos processos estudados e traçador quando há uma conotação dinâmica do acompanhamento do processo envolvido e que são os tipos de casos mostrados neste texto. ${ }^{4}$

*e-mail: cdonnici@terra.com.br
É notável que com o avanço tecnológico-científico houve a expansão do escopo e da aplicabilidade de traçadores e o seu uso expandiu-se em demasia, ocorrendo atualmente em quase todos os campos da ciência, tais como: medicina, biologia, fisiologia, nutrição, toxicologia, biotecnologia, química, agricultura, geociência e engenharia, ${ }^{5}$ com maior interesse para o estudo de processos ambientais, industriais e biológicos, ${ }^{3}$ cabendo destacar, no entanto, que a aplicação dos traçadores é muito mais comum nos estudos de caracterização de reservatórios de petróleo., ${ }^{2,3}$

É digno de nota que, de modo geral, os traçadores devem possuir as seguintes características: serem estáveis; estarem bem aderidos à fase de estudo e apresentarem uma densidade próxima à desta. Além disso, devem apresentar detecção inequívoca e quantificação em concentrações mínimas, serem atóxicos, não devendo interagir com materiais do meio e nem deixar resíduos; a injeção, a detecção e a análise devem ser realizadas sem introdução de perturbações ao sistema em estudo. ${ }^{1,3}$

\section{CLASSIFICAÇÕES DOS TRAÇADORES}

Há diversas classificações dos traçadores:

Origem dos traçadores - naturais e artificiais

\section{Traçadores naturais}

Dentre estes podemos citar: flora e fauna (acompanhamento qualitativo e quantitativo de espécies vegetais e animais), isótopos ambientais, temperatura e condutância específica. ${ }^{6}$

\section{Traçadores artificiais}

Compostos orgânicos e inorgânicos, tais como: pigmentos, sais e outros compostos como os fluocarbonados; entidades biológicas, como esporos; bactérias e vírus. ${ }^{6}$

\section{Utilização dos traçadores - internos e externos}

\section{Traçadores internos}

São elementos estáveis ou radioativos que ocorrem naturalmente 
no sistema sob estudo, geralmente de difícil quantificação. Não existem muitos exemplos de grande aplicabilidade, contudo, destaca-se o radônio. ${ }^{7,8} \mathrm{O}$ radônio possui dois isótopos aplicáveis ao estudo de águas subterrâneas. $\mathrm{O}^{222} \mathrm{Rn}$ que apresenta tempo de meia vida $\left(\mathrm{t}_{1 / 2}\right)$ de 3,8 dias, produzido pelo decaimento alfa do ${ }^{226} \mathrm{Ra}$ na série de decaimento do ${ }^{238} \mathrm{U}$, e o ${ }^{220} \mathrm{Rn}$ que apresenta tempo de meia vida $\left(\mathrm{t}_{1 / 2}\right)$ de 55,6 s, produzido pelo decaimento alfa do ${ }^{224} \mathrm{Ra}^{9}{ }^{9,10} \mathrm{O}$ radônio é um gás nobre, não sofre ionização e interação com a superfície do aquífero, apresenta alta atividade em águas subterrâneas, resultando em uma alta mobilidade do ${ }^{222} \mathrm{Rn}$ na transferência da matriz do aquífero/água ${ }^{10} . \mathrm{O}^{222} \mathrm{Rn}$ apresenta maior tempo de meia vida, como já citado, é o isótopo amplamente utilizado como traçador do fluxo de águas subterrâneas e de águas de superfície; nos córregos e rios, no litoral e na superfície dos reservatórios, e para estimar o tempo de residência de um aquífero. ${ }^{11} \mathrm{Um}$ artigo de revisão de Swarzenski traz informações sobre o estudo de águas subterrâneas, que inclui caracterização geoquímica do meio subterrâneo, definição da cinética de transporte de substâncias, interações água-rocha, determinação da idade geológica e impacto recebido pelo fluxo de água subterrânea. ${ }^{10}$ Os traçadores utilizados foram os radionuclídeos de ocorrência natural na série U/Th (Urânio, Tório, Rádio e Radônio), sendo efetuado um estudo mais aprofundado do radônio como traçador. ${ }^{10}$

A aplicabilidade do radônio como traçador em águas subterrâneas merece destaque em vários artigos, tais como: Tuccimei e colaboradore ${ }^{11}$ utilizaram o radônio para estudar a interação da água de superfície/a água subterrânea em circulação nos Lagos Verde e Nero, com a finalidade de avaliar a interação com as rochas do aquiífero, na região da província de Latina, na planície de Pontina, Itália; obtendo um volume médio de água nos lagos Verde e Nero de $540 \pm 160 \mathrm{~L} \mathrm{~s}^{-1}$. No estudo de águas subterrâneas, localizadas perto de um pólo produtor de gasolina em Zeitz na Alemanha, ${ }^{12} \mathrm{O}$ radônio foi utilizado para estudar a cinética e o tempo de residência da água nos reatores, pois estas águas foram tratadas em biorreatores sob condições anaeróbicas e contaminadas com benzeno. A concentração de radônio foi medida na saída do reator, onde um aumento da concentração do radônio indicou a diminuição do tempo de residência. Schubert e colaboradores estudaram o coeficiente de partição do radônio, entre as fases aquosa e orgânica, avaliando a eficiência do radônio como traçador de contaminação residual em aquífferos. ${ }^{13}$ Muitas substâncias puras possuem coeficiente de partição conhecido, mas existem poucos dados referentes ao coeficiente de partição do radônio em mistura orgânica. Estes autores estudaram os valores do coeficiente de partição nos combustíveis: diesel, gasolina, e querosene, que são os contaminantes usualmente encontrados em aquíferos. Em estudo realizado por Fan e colaboradore ${ }^{14}$ foi avaliada a distribuição do radônio em um aquífero contaminado com gasolina, um decréscimo da atividade de 7,38 \pm $1,68 \mathrm{~Bq} \mathrm{~L}^{-1}$ na zona não contaminada para $2,30 \pm 0,60 \mathrm{~Bq} \mathrm{~L}^{-1}$ na zona contaminada, evidenciando a grande afinidade do radônio pela fase orgânica, ou seja, um expressivo particionamento do radônio para a fase orgânica.

A utilização do traçador radônio tem alguns outros exemplos interessantes, como os descritos a seguir. $\mathrm{O}$ uso do radônio como traçador do magma expelido em um vulcão, ${ }^{15}$ verificou-se através do monitoramento do radônio no solo do vulcão Etna, na Sicília; a ligação entre o magma expelido/concentração do radônio no solo, nestas áreas as perturbações tectônicas como fraturas e falhas são caminhos preferenciais para o radônio expelido, tornando-o um localizador de falhas. A utilização do radônio como traçador de transporte de dióxido de carbono atmosférico em florestas, ${ }^{16}$ como o estudo realizado em uma floresta tropical perene e madura, próxima da floresta Nacional dos Tapajós no Pará, no qual o radônio se mostrou muito eficiente.

\section{Traçadores externos}

São traçadores adicionados ao sistema a ser estudado e podem ser classificados como fluorescentes, biológicos, químicos, radioativos e ativáveis. ${ }^{8}$ Neste artigo daremos detalhamento e ênfase aos traçadores externos, que são os mais comuns.

\section{TIPOS DE TRAÇADORES EXTERNOS}

\section{Traçadores fluorescentes}

São compostos orgânicos ou inorgânicos que apresentam fluorescência, tais como os corantes fluorescentes usuais: fluoresceína, isotiocianato de fluoresceína, rodamina-B, rodamina-WT, eosina, Evans Blue e urânio (Figura 1).

Um artigo de revisão de Smart ${ }^{17}$ traz informações toxicológicas de doze compostos fluorescentes utilizados como traçadores hidrológicos, destacando-se (devido ao baixo nível de detecção, menor que $100 \mu \mathrm{g} / \mathrm{L}$ ) entre estes a fluoresceína, eosina, rodamina WT e a rodamina-B (Figura 1), todavia a rodamina-B é muito carcinogênica, não podendo ser utilizada em ecossistemas aquáticos, pois atinge principalmente as larvas de moluscos e algas; somente a fluoresceína e a rodamina WT não são carcinogênicas. ${ }^{17}$ Alguns íons metálicos, como o urânio e os íons lantanídeos (samário, európio, térbio, disprósio e túlio), apresentam propriedades luminescentes em presença de luz ultravioleta, e diversas aplicabilidades como, por exemplo, aditivo fluorescente em porcelanas dentárias. ${ }^{18} \mathrm{O}$ fenômeno da fluorescência é técnica analítica, que pelo seu usual baixíssimo limite de detecção, geralmente transforma esses traçadores em sensores com alta sensibilidade analítica e baixo custo de análise em aparelho muito usado, conhecido como espectrofluorímetro. ${ }^{19}$

A aplicabilidade da fluoresceína (Figura 1) como traçador é muito ampla, podendo-se destacar seu uso recente como traçador de águas salobra ${ }^{20}$ e fluviais ${ }^{21}$ para medidas de processos de transporte, sendo que neste caso se observou que a estabilidade da fluoresceína não alcança o quarto dia de estudo e que o gás hexafluoreto de enxofre $\left(\mathrm{SF}_{6}\right)$ se mostrou mais estável. A fluoresceína é aplicável em estudos das interações de águas subterrâneas com águas de superfície em lagos, rios e outros meios aquáticos e no tratamento de água/água de esgoto, onde as águas subterrâneas contribuem significativamente para o volume total da água de superfície.

O fluxo de água pode ser monitorado utilizando-se três tipos de traçadores: um material inerte como o hexafluoreto de enxofre $\left(\mathrm{SF}_{6}\right)$, a fluoresceína e um biológico, como o bacteriófago PRD1. Neste caso o $\mathrm{SF}_{6}$ é utilizado como um traçador primário, para avaliar a direção e a velocidade do fluxo na superfície, sendo pouco reativo (biológica e quimicamente inerte), detectável em baixas concentrações. A fluoresceína é utilizada para estudar os sistemas sépticos e comparar a viabilidade em relação aos outros traçadores e o bacteriófago PRD-1 é utilizado como modelo de velocidade de migração de vírus humanos, permitindo assim a comparação com os outros traçadores. Nesses estudos pode-se utilizar somente um tipo de traçador, mas para se obter maior confiabilidade dos dados e estudo mais amplo devem-se utilizar os três tipos de traçadores no sistema aquífero. ${ }^{22,23}$

É destacável o uso da fluoresceína para desenvolvimento de diversos sensores fluorescentes, tais como os utilizados para: determinação de compostos orgânicos e amostras líquidas com alta sensibilidade (5-500 $\left.\mu \mathrm{g} \mathrm{L}^{-1}\right)$; $^{24}$ determinação de hidrocarbonetos policíclicos aromáticos (PAH), alcançando-se limites de detecção da ordem de $n g \mathrm{~mL}^{-1}$ para benzo[a]pireno $(0,9)$, naftaleno $(1,1) \mathrm{e}$ antraceno $(3,4)$; $^{25}$ determinação de BTEX (benzeno, tolueno, etilbenzeno e xilenos), no qual a fluoresceína foi estudada, contudo, não 
<smiles>O=C(O)c1ccccc1-c1c2ccc(=O)cc-2oc2cc(O)ccc12</smiles>

Fluoresceína<smiles>Cc1ccc2c(-c3ccc(N=C=S)cc3C(=O)O)c3ccc(=O)cc-3oc2c1</smiles>

Isotiocinato de fluoresceína<smiles>CCN(CC)c1ccc2c(-c3ccccc3C(=O)O)c3ccc(=[N+](CC)CC)cc-3oc2c1</smiles>

$\mathrm{Cl}^{-}$

Rodamina B<smiles>O=C(O)c1ccccc1-c1c2cc(Br)c(=O)c(Br)c-2oc2c(Br)c(O)c(Br)cc12</smiles>

Eosina<smiles>CCN(CC)c1ccc2c(-c3ccc(C(=O)O)cc3C(=O)O)c3ccc(=[N+](CC)CC)cc-3oc2c1</smiles><smiles>Cc1cc(-c2ccc(N=Nc3ccc4c(S(N)(=O)=O)cc(S([O])([O-])O[Na])c(N)c4c3O)c(C)c2)ccc1N=Nc1ccc2c([N+](=O)[O-])cc(S(=O)(=O)O[Na])c(N)c2c1O</smiles>

Evans Blue

Figura 1. Estrutura dos compostos fluorescentes: Fluoresceína, Isocianato de Fluoresceína, Rodamina B, Eosina Rodamina WT e Evans Blue

se mostrou aplicável para estudos em fluxo devido à sua retenção pela parte iônica ( $\mathrm{RCOO}^{-} \mathrm{Na}^{+}$) em sua estrutura (Figura 1). É digno de nota o estudo de Kleimeyer e colaboradore ${ }^{26}$ na determinação de fluoresceína em níveis de ultratraço (40 ppq, ou 4,0.10 $10^{-14} \mathrm{~g} \mathrm{~mL}^{-1}$ ) com o desenvolvimento de detectores de fluorescência de comprimento de onda múltiplo de alta sensibilidade para cromatografia líquida de alta eficiência (CLAE), demonstrando-se a potencialidade e sensibilidade ainda maior da fluoresceína como traçador. A aplicabilidade da fluoresceína como traçador com uso na área de medicina merece destaque em vários artigos, tais como: Orth e colaboradores, ${ }^{27}$ que utilizaram a fluoresceína para medir o volume de células vermelhas no sangue, onde esta se liga aos eritrócitos com o intuito de quantificar a perda de sangue após intervenção cirúrgica; Larsen, ${ }^{28}$ que utilizou a fluoresceína em fluorometria ocular e no estudo da metabolização desta no glucoronídeo correspondente quando da injeção intravenosa.

O isotiocianato de fluoresceína (FITC) (Figura 1) é um traçador que tem mostrado aplicabilidade em várias áreas, como no estudo da citometria de fluxo; como marcador fluorescente na conjugação com o anticorpo monocloconal murino (AcMn), que reage positivamente com hemácias de cães, e negativamente com leucócitos de humanos, obtendo-se média de positividade de 94,70 para as hemácias de cães e média de positividade de 0,03 para leucócitos humanos; ${ }^{29}$ na análise de aminoácidos quirais presentes nos alimentos, pelo método MEKC-LIFE, onde o isotiocianato de fluoresceína faz a separação dos aminoácidos L/D, que são detectados e quantificados em vinagre balsâmico, vinagre de cidra e vinho branco. ${ }^{30}$

A utilização de rodamina-WT e rodamina-B (Figura 1) como traçadores fluorescentes tem alguns exemplos interessantes como, respectivamente, aplicação para estudo de sedimentos contaminados no porto de Boston nos EUA $^{31}$ e determinação de tensoativos usados em larga escala, como o dodecil-benzenossulfonato de sódio em nível traço. ${ }^{32} \mathrm{~A}$ rodamina-WT e rodamina-B são muito utilizadas em hidrologia devido ao baixo custo, facilidade de detecção, usualmente com o emprego da técnica de injeção constante no campo para aplicação, assegurando a mistura por completo do traçador injetado, sendo injetados na parte de cima do rio em estudo (Figura 2). As amostras de água são coletadas regularmente em diferentes localidades e a concentração do traçador é analisada no espectrofluorímetro, determinando a quantidade de água requerida para diluir a solução do traçador injetado. Com a utilização destes traçadores fluorescentes, concentrações muito baixas podem ser medidas em pontos distantes ao longo do rio (longe da jusante). ${ }^{33}$

Os traçadores fluorescentes quando utilizados em reservatórios apresentam uma desvantagem em relação aos outros tipos de traçadores, pois muitas vezes sofrem processos de clivagem molecular, ou perdem suas propriedades fluorescentes nas temperaturas geotérmicas dos reservatórios, ou ainda são sensíveis a mudanças de $\mathrm{pH}$ e facilmente absorvidos pelas formações do reservatório. ${ }^{8,34,35}$ Outros exemplos da aplicação ambiental de traçadores fluorescentes podem ainda ser citados: a rodamina tem sido utilizada para avaliar a deposição de pesticidas e xenobióticos no solo por apresentar adsorção diferenciada, ${ }^{36}$ rodamina-B e complexos com íons lantanídeos são utilizados no estudo do transporte de colóides em meios porosos, na contaminação de águas subterrâneas e solo $;^{37}$ no estudo da erosão e morfodinâmica de rochas costeiras. ${ }^{38}$

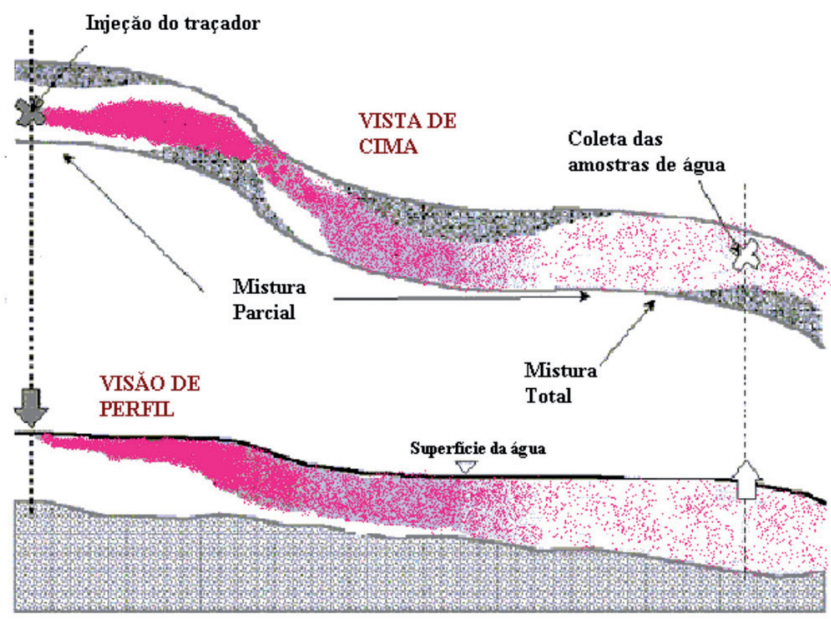

Figura 2. Traçadores na investigação das interações da água de superfície e subterrânea. Adaptada de www.connectedwater.gov.au/framework/artificial_tracers.html

É destacável o uso recente de traçadores fluorescentes neurais, ou trans-sinápticos, como a 5-benzofurancarboximiamida, o 
<smiles>N=C(N)c1ccc2oc(/C=C/c3cc4cc(C(=N)N)ccc4o3)cc2c1</smiles>

Figura 3. Estrutura do traçador fluorescente True Blue (TB)

2,2'-(1E)-1,2-bis-etenil-hidrocloreto conhecido como True Blue (TB) (Figura 3), um estilbeno substituído conhecido como FluorGold (FG), Fluor-Esmeralda (FE) e o Fluor-Rubi (FR) ${ }^{39,40}$ FE e FR - que são, na verdade, tipos de dextran conjugados - dextranfluoresceína (FE) e dextran-tetrametilrodamina (FR) (o polissacarídeo dextran é obtido a partir da solução de açúcar infectada com a bactéria Leuconostoc mesenteroides e possui uma pressão osmótica similar ao plasma sanguíneo). ${ }^{41}$ Os traçadores fluorescentes TB, FG, FE e FR são utilizados em ratos para estudar as conexões entre diferentes grupos de neurônios, bem como sua maturação e plasticidade, os neurônios que regeneram axônios, ${ }^{39}$ e a projeção moto-neurônica do músculo. ${ }^{40}$

A eosina (Figura 1) tem várias aplicações descritas na literatura, contudo destacam-se os exemplos recentes de seu uso como traçador: no estudo in situ dos parâmetros de um reservatório de água, tais como tamanho, porosidade, fluxo de água, transporte de contaminantes, e a influência da heterogeneidade do reservatório no fluxo de água; ${ }^{42}$ Brouyere e colaboradores ${ }^{43}$ estudaram, em águas subterrâneas, os mecanismos de migração de solutos e a matriz das rochas em um aquífero na Bélgica.

Um traçador fluorescente que merece destaque é o conhecido como Evans Blue (Figura 3) que não é usualmente fluorescente, ${ }^{44}$ mas que assim se torna quando ligado a algumas proteínas específicas e que tem mostrado potenciais aplicações para o estudo de problemas neurológicos, ${ }^{45}$ como edemas cerebrais, apoptose neural e a permeabilidade da barreira sangue - cérebro em ratos ${ }^{46}$ onde o Evans Blue se conjuga com a albumina, permitindo uma rápida visualização das células danificadas. ${ }^{47}$

Outro agente usualmente conhecido pela sua radioatividade, mas não pela sua fluorescência, é o urânio na forma de U(VI); esta sua propriedade fluorescente já foi explorada, por exemplo, para determinação de fraturas em rochas graníticas e a velocidade do fluxo de águas subterrâneas, sendo que outros materiais fluorescentes como Th (IV) e Eu (III) também foram utilizados para esta finalidade. ${ }^{48}$

\section{Traçadores biológicos}

Formam uma classe separada de traçadores, uma vez que não são solutos, mas sim uma suspensão de partículas submicroscópicas, que na água se comportam como partículas coloidais. De modo geral, os traçadores biológicos devem apresentar as seguintes características: fácil crescimento em grandes culturas, não serem patogênicos (para animais, plantas e humanos), não estarem presentes no meio em estudo, não terem movimento próprio, entre outros..$^{34,49,50}$ Os principais micro-organismos utilizados como traçadores são: vírus, bactérias, leveduras, protozoários e esporos. As bactérias são os microrganismos comumente utilizados em estudos hidrológicos, enquanto o uso de leveduras e protozoários é limitado devido ao tamanho e tempo de sobrevivência; os vírus apresentam o inconveniente de alguns serem patogênicos aos seres humanos. ${ }^{51}$ Microrganismos não patogênicos, como os esporos, têm sido utilizados para seguir o destino de patógenos humanos, em estudos de aquíferos, mas sua análise requer filtragem e exame microscópico. ${ }^{33}$ Algumas bactérias, como Microbacterium pseudomonas e Staphylococcus, são utilizadas para estudar características físico-químicas, transporte, mobilidade de bactérias em reservatórios de água. ${ }^{52}$

Dentre os numerosos traçadores biológicos possíveis, os bacteriófagos apresentam-se como os mais vantajosos, por serem vírus de dimensões muito reduzidas, específicos para uma bactéria hospedeira e, geralmente, serem inócuos para qualquer outro organismo. Os mais utilizados em estudos hidrogeológicos são de origem marinha, para evitar a existência da bactéria hospedeira nos aquíferos a serem estudados. Como exemplo, bacteriófagos marinhos (H4/4, H6/1 e H40/1) foram utilizados para estudar a circulação, o transporte e a propagação de bactérias e outros contaminantes no lago de Genebra, Suíça. ${ }^{53}$ Os bacteriofágos MS-2 e PRD1 são utilizados para estudar a contaminação por vírus patógenos humanos de um aquífero. ${ }^{54}$ Esses traçadores apresentam menores limites de detecção que os traçadores químicos e seu impacto ambiental é praticamente nulo, dada a sua curta persistência. No entanto, estes agentes têm como inconvenientes sua forte interação com o meio físico (não são conservativos) e a necessidade de um alto grau de sofisticação para sua cultura. ${ }^{34,49,50}$

\section{Traçadores químicos}

São compostos não-radioativos, tais como haletos (iodetos, brometos), ânions ou moléculas orgânicas que são detectáveis por análises químicas. ${ }^{8}$ Apresentam, porém, geralmente limitações de estabilidade térmica, reatividade em potencial e altos limites de detecção. Apesar dos altos limites de detecção, o baixo custo do material não-radioativo permite a injeção de grandes quantidades, compensando a sensibilidade do método. A análise dos traçadores químicos pode ser feita por cromatografia líquida de alta eficiência, ressonância magnética nuclear e espectrometria de massas. ${ }^{8}$ Haletos de metais alcalinos, como o iodeto de potássio e o brometo de potássio, são muito utilizados como traçadores, pois apresentam menor tendência à interação com a formação de um reservatório. ${ }^{8}$ Os brometos e os ácidos flúor-benzóicos (FBAs) são aplicáveis no estudo dos processos ambientais como processos de erosão, transporte de massa, entre outros. ${ }^{23}$ Os traçadores químicos também são empregados como agentes de contraste, sendo os mais utilizados: complexos de gadolínio, sulfato de bário e compostos iodados. Os complexos de gadolínio são geralmente usados como agente de contraste em imagem por ressonância magnética (IRM). O sulfato de bário e compostos iodados são utilizados em análise por raio-X. O sulfato de bário é utilizado somente no trato digestivo, administrado como uma lavagem intestinal. Os compostos iodados podem ser orgânicos (iônicos ou não iônicos), sua concentração é expressa mgI/ $\mathrm{mL}$ e podem ser aplicados em quase todas as partes do corpo, sendo os mais utilizados: ácido diatrizóico, Iopamidol, Iohexol, Ioxilan e Iodixanol (Figura 4) ${ }^{55}$ Estes compostos à base de iodo têm sido utilizados para angiografia, urografia ou tomografia computadorizada, absorvem radiação (em escala proporcional à concentração de iodo na solução) e, em tese, não deveriam interagir com o organismo, mas podem causar efeitos colaterais como reações de hiper-sensibilidade sistêmica, reações cardíacas (hipertensão, taquicardia, arritmia), efeitos vasculares (agregação plaquetária, vasoconstrição, trombose) e efeitos renais. O rim, como responsável pela maior parte da excreção de substâncias, é alvo de componentes tóxicos, incluindo os agentes de contraste (que já são o segundo maior agente nefrotóxico na prática clínica). Os agentes de contraste são filtrados pelos glomérulos e não são secretados nem reabsorvidos nos túbulos. A importância do estudo do impacto nos rins se deve ao aumento dos procedimentos clínicos que utilizam esses compostos. ${ }^{56}$

Os complexos de gadolínio com diversos ligantes de grande volume molecular como Gd albumina (MS-325), Gd-derivados do DOTA, Gd-dendrimeros são utilizados no estudo das funções 
<smiles>CC(=O)Nc1c(I)c(NC(C)=O)c(I)c(C(=O)O)c1I</smiles>

Ácid o Diat rizóico<smiles>CC(O)C(=O)Nc1c(I)c(C(=O)NC(CO)CO)c(I)c(C(=O)NC(CO)CO)c1I</smiles>

Iopamidol<smiles>CC(=O)N(CC(O)CO)c1c(I)c(C(=O)NCC(O)CO)c(I)c(C(=O)NCC(O)CO)c1I</smiles>

Iohe xol<smiles>CC(=O)N(CC(O)CO)c1c(I)c(NCCO)c(I)c(NCC(O)CO)c1I</smiles>

Ioxilan<smiles>CC(=O)N(CC(O)CN(C(C)=O)c1c(I)c(C(=O)NCC(O)CO)c(I)c(C(=O)NCC(O)CO)c1I)c1c(I)c(C(=O)NCC(O)CO)c(I)c(C(=O)NCC(O)CO)c1I</smiles>

Iodix anol

Figura 4. Estrutura dos traçadores químicos: Ácido Diatrizóico, Iopamidol, Iohexol, Ioxilan e Iodixanol

renais ou para propósitos celulares (fagocitose intrarenal em doenças inflamatórias renais). ${ }^{57}$ Em relação à obtenção de imagens por ressonância magnética (IRM), pode-se destacar que a partir do complexo de gadolínio com ácido dietilenotriamina penta-acético (Gd-DTPA) e seus derivados podem-se obter imagens dos rins ${ }^{58} \mathrm{e}$ a utilização de alguns derivados porfirínicos conduz à obtenção de imagens de tumores. ${ }^{59}$

O estudo recente dos ácidos perfluorados como traçadores é digno de nota, pois apesar destes compostos serem contaminantes atmosféricos ambientais, sua alta hidrossolubilidade tem mostrado aplicabilidade mundial como descritores de distribuição espacial vertical e horizonte em oceanos, possibilitando o desenvolvimento de metodologias para estudo do transporte de água em correntes marítimas. ${ }^{60} \mathrm{O}$ amplo escopo e a larga aplicabilidade de traçadores para estudos oceânicos podem ser avaliados no artigo de revisão de England e colaboradores (com 147 referências citadas). ${ }^{61}$ Neste artigo pode-se concluir que os traçadores químicos têm sido utilizados para estudar e simular a circulação em modelos oceânicos, podendo-se citar vários exemplos, tais como: o trítio, clorofluor carbonos (CFCs), radiocarbonos produzidos naturalmente, oxigênio, silicatos, fosfatos, isótopos de carbonos em compostos orgânicos e inorgânicos e certos gases nobres (como hélio, argônio). É notória a constatação de que com a utilização destes traçadores químicos podem ser obtidas informações cruciais que não seriam obtidas com os dados de correlação entre temperatura e salinidade $(\mathrm{T}-\mathrm{S}){ }^{61}$

$\mathrm{O}$ gás hexafluoreto de enxofre $\left(\mathrm{SF}_{6}\right)$, como traçador, apresenta diversas aplicabilidades interessantes e únicas, tais como: traçador geotérmico, na avaliação do fluxo de água do reservatório geotérmico artificial, destacando-se o fato de que o $\mathrm{SF}_{6}$ conserva a massa injetada por até $25 \mathrm{~h}$ (estudo efetuado em Rosemanowes, no sudeste da Inglaterra); ${ }^{62}$ como traçador de poluição do ar; ${ }^{63}$ na avaliação da produção e emissão do gás metano a partir da dieta de ruminantes ${ }^{64}$ e como traçador oceanográfico. ${ }^{65,66}$

Uma outra aplicação muito interessante dos traçadores químicos e digna de destaque é o estudo da dieta de baleias orca (Orcinus orca) no Pacífico Norte, com o uso de isótopos estáveis de carbono $\left({ }^{13} \mathrm{C}\right)$ e nitrogênio $\left({ }^{15} \mathrm{~N}\right) \cdot{ }^{67}$ Neste estudo os traçadores químicos utilizados foram obtidos por extração lipídica com os isótopos marcados de carbono e de nitrogênio; concentrações de poluentes orgânicos persistentes (POP), tais como DDTs/PCBs e hexaclorociclo-hexano $(\mathrm{HCH})$ e ácidos poli-insaturados, foram encontradas em amostras de gordura de baleias mortas. Cabe ressaltar que até mesmo os maiores predadores exibem sinais adquiridos de suas vítimas, servindo como indicadores das espécies consumidas e das regiões de onde provêm. Neste contexto, os traçadores químicos são utilizados para avaliar a transferência de poluentes no ambiente marinho e sua relação com a dieta das baleias, pois no Pacífico Norte há dois tipos de baleias, nomeadas de "residentes" e "transitórias", diferindo-se por sua genética, acústica, morfologia e alimentação. As transitórias matam somente mamíferos marinhos e as residentes consomem peixes, especialmente o salmão. Estes estudos especialmente forneceram dados sobre as baleias do grupo off-shore, das quais se possuíam pouquíssimas informações sobre sua dieta, e confirmou-se que as baleias se alimentam em regiões ao sul da Califórnia, longe do Pacífico Norte. ${ }^{67}$

Destaca-se também o uso recente de boretos de metais de transição como traçadores radioativos, até recentemente pouco explorados, pelo fato de que não há isótopos estáveis e radioativos no caso do boro $-19 \%\left({ }^{10} \mathrm{~B}\right)$ e $81 \%\left({ }^{11} \mathrm{~B}\right)$. Schmidt e colaboradores ${ }^{68}$ descrevem o uso de espectrometria de massas para acompanhamento deste traçador.

\section{Traçadores radioativos}

São átomos ou moléculas marcados isotopicamente e cujos átomos estudados são radioativos, sendo o tipo de traçador mais comumente utilizado em testes, pois apresenta baixos limites de detecção. Os radioisótopos utilizados dependem das propriedades do material, energia de radiação e tempo de meia vida. Os traçadores radioativos são bons para medidas contínuas, pois emitem radiações (gama ou beta) com grande sensibilidade e baixa interferência. Teoricamente, traçadores radioativos são capazes de confirmar todos os resultados obtidos com os traçadores fluorescentes, mas o inverso não ocorre, pois os traçadores radioativos apresentam como desvantagens a dificuldade de manipulação de material radioativo e possível contaminação do meio ambiente. Esses fatores têm contribuído para o uso preferencial de materiais não radioativos como traçadores em estudos biológicos e ambientais..$^{1,8,69,70}$ Os radioisótopos podem ser incorporados em uma 
grande variedade de compostos orgânicos e inorgânicos, e existe uma grande flexibilidade para aplicações, como os dois exemplos a seguir: a determinação de defeitos em semicondutores em combinação com espectroscopia de luminescência - a ação laser de $\mathrm{ZnO}$ que contém cobre como impurezas, cuja detecção é feita pelas partículas $\beta$ - emitidas pelo isótopo radioativo ${ }^{67} \mathrm{Cu},{ }^{71} \mathrm{O}^{68} \mathrm{Ge}(\mathrm{OH}){ }_{4}$ que é utilizado para estudar a distribuição e transporte do $\mathrm{Si}(\mathrm{OH})_{4}$ em plantas que acumulam $\mathrm{Si}^{72}$. Contudo, deve-se destacar que a importância deste tipo de traçadores na Medicina é indiscutível, existindo muitos trabalhos de revisão recentes que relatam o enorme escopo e aplicabilidade destes traçadores em áreas estratégicas, tais como: tomografia de aniquilação de pósitron (PET),${ }^{73}$ nos estudos do cérebro e doenças neurais, aplicação de PET na forma de traçadores específicos $\left({ }^{18} \mathrm{~F} \mathrm{e}{ }^{11} \mathrm{C}\right)$ e, desta forma, pode-se obter o diagnóstico precoce de doenças como Parkinson e Alzheimer, além da detecção de outras desordens neuro-cerebrais como isquemias, gliomas e esquizofrenia. Compostos específicos como transmissores, metabólitos, ligantes receptores e alguns parâmetros biológicos (atividade metabólica, sinal receptor) foram marcados radioativamente e utilizados como traçadores em alguns casos das doenças citadas; tomografia de aniquilação de pósitron (PET) na geração de novos fármacos, ${ }^{74}$ marcação direta dos fármacos com os emissores de pósitron ${ }^{11} \mathrm{C}{ }^{13} \mathrm{~N},{ }^{15} \mathrm{O}$ e ${ }^{18} \mathrm{~F}$, possibilitando a quantificação da distribuição in vivo e estudo da cinética do fármaco marcado, e posterior correlação entre os efeitos farmacológicos observados e o sítio receptor. Tais novas tecnologias, com o uso de radionuclídeos emissores de radiação gama, tais como ${ }^{99 \mathrm{~m}} \mathrm{Tc},{ }^{111} \mathrm{In},{ }^{123} \mathrm{I}$ e ${ }^{153} \mathrm{Sm}$ ou com emissores de pósitron $\left({ }^{11} \mathrm{C}\right.$, ${ }^{13} \mathrm{~N},{ }^{15} \mathrm{O}$ e ${ }^{18} \mathrm{~F}$ ), permitem a imagem do local específico de receptores no cérebro, no trato gastrointestinal, nos pulmões ou na córnea ocular e possibilitam não só a correlação entre efeitos farmacológicos observados e o sítio preciso de interação, como também uma ferramenta poderosa para avaliação da liberação do fármaco no organismo do paciente, com reprodutibilidade, e confiabilidade. Em outro artigo de revisão, de Kairemo e colaboradores, ${ }^{75}$ é notória a conclusão de que com a ajuda de compostos radiomarcados e da técnica de imagem PET, o desenvolvimento de novos fármacos é acelerado, especialmente para drogas anticâncer.

A aplicabilidade dos traçadores radioativos na Medicina Nuclear é notória, relacionando resposta fisiológica de um ser vivo e dispositivos externos de imagem. Os dispositivos de imagem por tomografia computadorazida (SPECT) e PET são quantitativos, analisando a concentração do traçador como, por exemplo, o monitoramento do radiofármaco $([18 \mathrm{~F}]-\mathrm{FDG})$ por uma máquina fotográfica gama no tratamento anticâncer. ${ }^{76}$ Cabe destacar também a grande aplicabilidade dos traçadores radioativos para investigação de imagens tridimensionais (3D) no organismo de animais vivos. Destacando-se a física de imagem molecular; seleção da radiação emitida pelo traçador, o processo de reconstrução tomográfica e a utilização das técnicas de tomografia computadorizada de emissão de fótons (SPECT) e PET para produção de imagens 3D obtidas a partir do animal. ${ }^{77}$

Os traçadores radiativos específicos com alta atividade são ferramentas para o estudo de exposição a diferentes formas químicas, dentre estas as formas essenciais e tóxicas dos elementos, mesmo que em baixas concentrações e por tempo prolongado. ${ }^{78} \mathrm{Um}$ recente livro enciclopédico de revisão de Chinkes ${ }^{79}$ sobre o uso dos traçadores radioativos aborda aspectos relacionados à síntese, purificação, quantificação e decomposição destes traçadores e discute a importância da sua utilização e manipulação seguras. Esses agentes são empregados no estudo do comportamento de espécies químicas em diversos processos de transformação, como se pode verificar nos inúmeros exemplos citados por Ambe e Enomoto ${ }^{80} \mathrm{em}$ um manual específico da área.

Os traçadores radioativos também são utilizados como agente de contraste como, por exemplo, os complexos DTPA-99m Tc (ácido dietilenotriaminopentácetico marcado com tecnécio 99m); EDTA- ${ }^{51} \mathrm{Cr}$ (ácido etilenodiaminotetracético marcado com cromo 51) têm sido utilizados no estudo da taxa de filtração glomerular. ${ }^{81}$

$\mathrm{O}$ uso de traçadores radioativos, especialmente os emissores gama, gera ferramenta analítica poderosa para análise de elementos metálicos tóxicos na biosfera e no organismo humano em nível de traço (ng a mg por quilo), especialmente por meio da técnica de cintilação líquida. Esta técnica é especialmente notável pela alta especificidade e sensibilidade, como pode-se observar no trabalho de revisão deste tema de Bonardi e colaboradores. ${ }^{78}$

A utilização de traçadores radioativos também tem fornecido imensa contribuição para o estudo de processos ambientais, tais como o estudo dos processos de erosão, ${ }^{82}$ onde são utilizadas partículas marcadas com metais $\left({ }^{137} \mathrm{Cs},{ }^{210} \mathrm{~Pb},{ }^{7} \mathrm{Be},{ }^{234} \mathrm{Th},{ }^{56} \mathrm{Fe},{ }^{60} \mathrm{Co}\right)$; o isótopo radioativo do césio, o ${ }^{137} \mathrm{Cs}$ é usado para estudar a taxa de erosão por períodos prolongados, pois apresenta meia vida de 30 anos; o ${ }^{210} \mathrm{~Pb}$ apresenta meia vida de 20 anos e o ${ }^{7} \mathrm{Be}$ meia vida de 53 dias, são formados naturalmente na atmosfera e depositados na superfície por precipitação, distribuindo-se em diferentes profundidades do solo. Esses dois elementos, quando utilizados em conjunto como traçadores, fornecem uma identificação mais precisa do processo de erosão nos rios. ${ }^{14} \mathrm{C}$ e ${ }^{15} \mathrm{~N}$ são amplamente utilizados em estudos de assimilação e translocação em ecossistemas. ${ }^{83}$ Gramas de pradaria e/ou outro material presente em um ecossistema podem ser marcados in situ com ${ }^{14} \mathrm{C}$, encontrado na forma de ${ }^{14} \mathrm{CO}_{2}$, e assim pode-se acompanhar o fluxo da fotoassimilação nas plantas e no solo, com posterior cálculo da quantidade de carbono translocado e absorvido pelas raízes das plantas; se o estudo em questão for efetuado em presença de ${ }^{15} \mathrm{~N}$ pode-se avaliar também a contribuição do nitrogênio derivado do solo orgânico e do nitrogênio alocado nas raízes das plantas. ${ }^{84}$

Dentre os vários traçadores radioativos, o trítio, na forma de água tritiada $\left(\mathrm{T}_{3} \mathrm{O}\right)$ é considerado o melhor traçador para campos geotérmicos, o que é indicado em vários textos de revisão. ${ }^{85} \mathrm{O}$ trítio é mais barato que a maioria dos radioisótopos, mas é mais difícil de medir, devido à baixa energia de radiação e necessita de equipamento mais sofisticado para sua detecção. ${ }^{8} \mathrm{O}$ trítio é amplamente utilizado como traçador na recuperação secundária do petróleo. Adicionado junto à água injetada para avaliar o fluxo de água e barreiras geológicas ou canais de fluxo, Ahmad e colaboradores ${ }^{86}$ utilizaram o trítio juntamente com os isótopos ambientais $\left({ }^{18} \mathrm{O},{ }^{2} \mathrm{D}\right)$ no reservatório de petróleo Chakwal, no Paquistão; avaliaram o fluxo de água no aquífero e a contribuição da água injetada e concluíram que a água de produção é uma mistura da água de formação com a água injetada, sendo que a contribuição da água injetada variou de 67 a $80 \%$.

Podemos destacar a importância e a grande aplicabilidade do trítio como traçador em águas subterrâneas, através de vários exemplos: o trítio juntamente com os isótopos de oxigênio, hidrogênio e enxofre $\left({ }^{18} \mathrm{O},{ }^{2} \mathrm{D},{ }^{34} \mathrm{~S}\right)$ foram utilizados no deserto de Negev, em Israel, para identificação das fontes poluidoras das águas subterrâneas de um complexo industrial e prevenir futuras contaminações ${ }^{87}$ na avaliação da contaminação por nitrato, o trítio/hélio-3 $\left({ }^{3} \mathrm{H} /{ }^{3} \mathrm{He}\right)$ e clorofluorcarbonos (CFCs) foram aplicados na ilha de Jeju, Coréia, para obter informações do fluxo de água no aquífero vulcânico e estimar a contaminação por nitrato provinda da atividade humana, ${ }^{88}$ obtendo-se uma concentração de nitrato de $10 \mathrm{mg} \mathrm{NO}_{3}-\mathrm{N} / \mathrm{L}$ no litoral da Islândia; ${ }^{88,89}$ na obtenção de informações de um aquífero próximo à cidade de Nova York, utilizou-se a mistura de trítio e hélio triogênico ${ }^{3} \mathrm{H} /{ }^{3} \mathrm{He}$ em um aquífero; ${ }^{90}$ e com a combinação de traçadores antropogênicos (CFC-11, $\left.\Delta{ }^{14} \mathrm{C},{ }^{3} \mathrm{H}\right)$ é possível efetuar o cálculo da concentração de $\mathrm{CO}_{2}$ antropogênico, usualmente difícil, e estimar-se sua distribuição no oceano. ${ }^{91}$ 


\section{Traçadores ativáveis}

São aqueles que podem ser introduzidos no estado inativo dentro do sistema a ser estudado e, posteriormente, serão transformados em radioativos (daí o termo ativáveis) por "irradiação" em instalações nucleares, mais especificamente por irradiação de nêutrons para facilitar a análise por ativação neutrônica. Estes traçadores oferecem vantagens semelhantes aos radioativos, sem o problema de causar danos à saúde e ao ambiente e além do mais podem ser obtidos em grandes quantidades com custo relativamente baixo. ${ }^{8}$ Cabe destacar que o traçador deve apresentar alta seção de choque para nêutrons térmicos, o radionuclídeo produzido deve emitir radiação gama para medição por espectrometria de raios-gama e ter bom tempo de meia vida para permitir a contagem após o período de resfriamento entre o fim da irradiação e a medida da atividade. ${ }^{8}$ A quantidade do elemento estável usada como traçador geotérmico depende do fluxo de nêutrons disponível, com um alto fluxo de nêutrons é necessária pequena quantidade de elemento estável para a análise por ativação. Para utilização de um traçador ativável é necessário: a escolha e introdução de uma forma química do traçador no sistema a ser estudado, retirada cuidadosa das amostras com o material que será marcado evitando contaminação externa, submissão dessas amostras à análise por ativação neutrônica para identificação do produto da reação nuclear, bem como quantificação do traçador presente no material. ${ }^{1-3,8,92}$. Os traçadores ativáveis apresentam vantagens em relação aos outros tipos de traçadores quando utilizados em reservatórios, pois não sofrem processos de clivagem e, na maioria dos casos, são estáveis em altas temperaturas e em variações de $\mathrm{pH}$, e não tóxicos.

A análise por ativação neutrônica geralmente não é muito conhecida e baseia-se na habilidade de induzir uma reação nuclear em átomos de determinados elementos. Como resultado, isótopos radioativos são formados e podem ser reconhecidos por sua radiação. ${ }^{93}$ Esta técnica é uma combinação de processos químicos e nucleares selecionados para otimizar a precisão e exatidão do elemento traçador em análises químicas ou estudo de uma alta diluição do traçador. Cabe destacar que poucos métodos analíticos oferecem a versatilidade e a sensibilidade encontradas na análise por ativação neutrônica. Devido ao fato dos nêutrons ativarem o núcleo de um átomo e não a camada eletrônica, esta técnica permite a determinação quantitativa e a identificação qualitativa dos elementos, com o monitoramento das radiações. ${ }^{8,94}$ Dos vários tipos de radiações que podem ser emitidas, a que melhor possibilita selecionar e determinar simultaneamente os elementos presentes na amostra é a radiação gama. Entre as vantagens da técnica destacam-se a variedade de amostras analisáveis, a capacidade de análise multielementar, a sensibilidade e a seletividade. ${ }^{95}$ Esta análise tem dois parâmetros a ser levados em conta que são a seção de choque do nuclídeo alvo e o fluxo de nêutrons que induz a reação nuclear, sendo a atividade induzida diretamente proporcional a ambos, pois para que um elemento seja determinado por esta técnica é necessário que possua seção de choque adequada à ativação e o fluxo de nêutrons seja sufi- cientemente intenso. ${ }^{95} \mathrm{~A}$ seção de choque representa a probabilidade de um projétil atingir um núcleo atômico e assim iniciar a reação. Um terceiro parâmetro, a meia vida do radionuclídeo formado determina o tempo de irradiação necessário para, sob um determinado fluxo, se obter uma atividade adequada para a contagem. A contagem das amostras ativadas em reator nuclear é feita com o espectrômetro gama (Figura 5). O esquema eletrônico é semelhante ao da espectrometria alfa, porém a contagem não requer vácuo uma vez que as radiações gama são de maior alcance, somente o detector fica sob o vácuo. ${ }^{96}$

A radiação gama interage com o detetor e esta interação é convertida em pulsos elétricos que são posteriormente amplificados e separados pelo analisador multicanal (Figura 5). Os dados são então armazenados e o resultado é dado em contagem por canal, gerando um espectro. A radiação gama incidente é característica de cada emissor e a contagem obtida é proporcional à atividade da amostra. ${ }^{96}$ É destacável o uso do ${ }^{50} \mathrm{Cr}$ para estudar o cromo como inibidor da insulina em animais e humanos ${ }^{97}$ e dentre os numerosos traçadores ativáveis possíveis, destacam-se alguns íons lantanídeos, como samário, európio, térbio, disprósio e túlio que além de apresentarem propriedades luminescentes, ${ }^{18}$ como já citado, são também bons traçadores ativáveis.

A utilização de traçadores ativáveis tem fornecido imensa contribuição para o estudo de processos ambientais, tais como: a utilização dos elementos terras raras ( $\mathrm{La}, \mathrm{Ce}, \mathrm{Nd}, \mathrm{Sm}, \mathrm{Eu}, \mathrm{Dy}$ e Yb) no estudo da erosão e deposição de sedimentos $;{ }^{98}$ o estudo de agregação e translocação do solo, no qual partículas de cerâmica foram marcadas com disprósio e aplicadas no solo, quantificadas e facilmente detectadas por análise por ativação neutrônica, uma esfera de $300 \mu \mathrm{m}$ foi detectada em $5 \mathrm{~g}$ de solo; ${ }^{99} \mathrm{o}$ uso de európio e térbio como traçadores em partículas de sedimento marcadas, para estudar padrões de dispersão em um estuário inglês, ${ }^{94} \mathrm{e}$ o estudo dos hábitos alimentares de animais e estabelecimento de sua cadeia alimentar. ${ }^{100}$ Neste último estudo, que é digno de nota, Jester e colaboradores, ${ }^{100}$ marcaram alguns tipos de sementes com disprósio, índio e samário, que foram posteriormente espalhadas no campo, os roedores foram capturados e as amostras de fezes analisadas para determinar a concentração do traçador presente, a quantidade e o tipo de sementes ingeridas por cada tipo de animal.

Uma aplicação importantíssima dos traçadores ativáveis deve ser destacada, estes agentes são muito empregados em petroquímica para a caracterização de reservatórios de petróleo no processo denominado recuperação secundária, onde são injetados juntamente com água. ${ }^{17,101}$ Normalmente a estrutura do reservatório é dividida em camadas contendo heterogeneidades, resultando em variações direcionais na extensão do fluxo, barreiras de permeabilidade que impedem um bom deslocamento do petróleo pela água injetada. ${ }^{101}$ Juntamente com a água injetada, traçadores são adicionados para avaliar o movimento da água e o processo de recuperação secundária (Figura 6). ${ }^{101}$

Tal aplicação dos traçadores é de grande relevância não só científica, mas financeira desde que a aparente riqueza petrolífera de uma nova

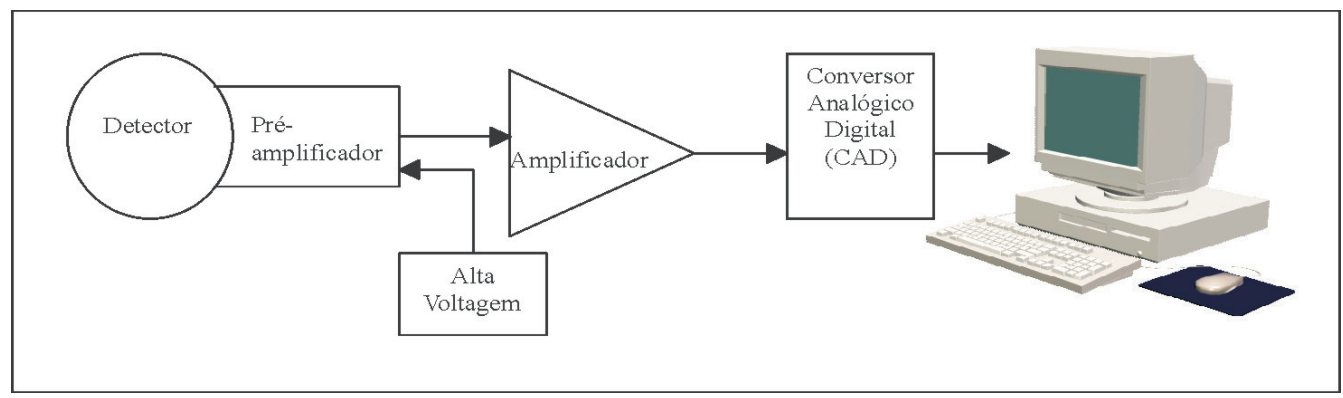

Figura 5. Representação esquemática de um espectrômetro gama 


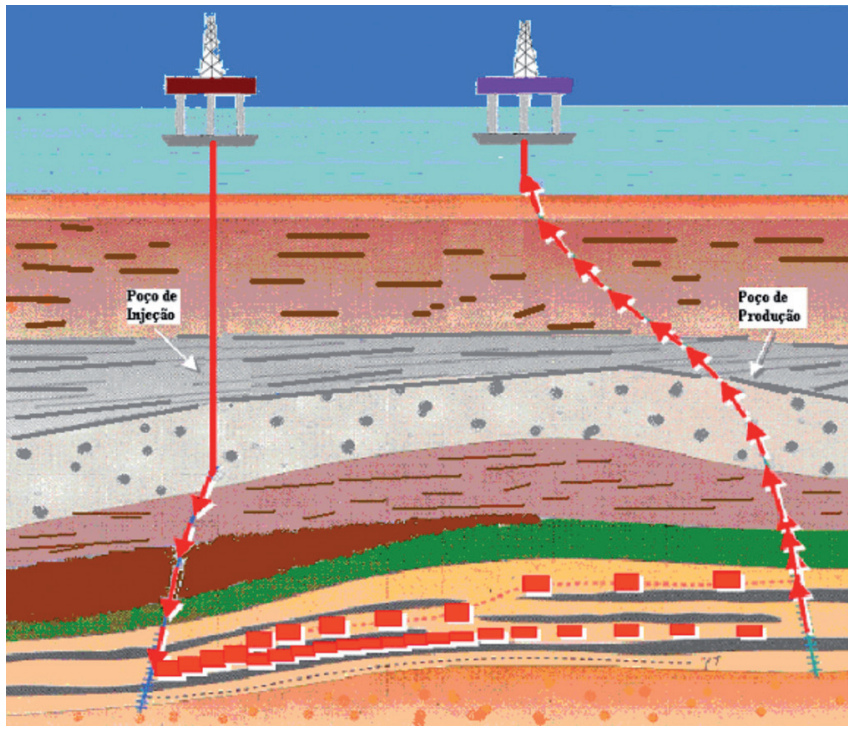

Figura 6. Movimento do traçador entre os poços de um reservatório. Adaptada de Guidebook-IAEA 2004

região produtora de petróleo, ou mesmo de uma região já explorada, pode gerar enganos na avaliação geral do potencial total produtor de petróleo, pois o que se pode estar realmente descobrindo não é um novo poço de petróleo, mas um sub-afluente do mesmo poço original. Além do mais, com agentes traçadores pode-se estimar o volume total real de petróleo que um poço petrolífero venha a produzir e a real independência de outros poços da região, obtendo-se informações valiosíssimas nesta nova situação mundial de crescente escassez de petróleo.

Os traçadores eficientes são aqueles que não se atrasam ou se particionam por interação com as rochas e/ou fluidos não aquosos presentes nos reservatórios. ${ }^{3} \mathrm{Na}$ verdade, neste ponto cabe esclarecer que se podem estudar dois tipos de traçadores: os hidrossolúveis, que devem ser dispersados na emulsão petróleo-água e que são utilizados principalmente para o conhecimento da intercomunicabilidade dos diferentes poços de petróleo, e os lipossolúveis, que devem ser dispersos na fase do petróleo e que podem ser facilmente utilizados para o conhecimento da quantidade de óleo do poço. De qualquer forma, para os dois tipos de traçadores é importante o conhecimento de seu coeficiente de partição para a avaliação quantitativa do volume de óleo do(s) poço(s).

O conhecimento atual sobre traçadores em petroquímica deve-se à pesquisa em laboratórios com programas computacionais, a experimentos em campos de petróleo, ${ }^{102} \mathrm{a}$ investigações da movimentação de águas subterrâneas, ${ }^{103}$ a experimentos com traçadores atmosféricos e várias pesquisas sobre migração de espécies radioativas em solos. ${ }^{102}$ Mesmo com essas pesquisas, os resultados de uma área investigada não podem ser usados para todos os campos, devido a mudanças nas condições experimentais.

Os objetivos gerais de um teste com traçador de aplicação petroquímica são: representar a direção do fluxo e suas conexões; avaliar a varredura volumétrica entre o injetor e o produtor; detectar barreiras ao fluxo; estimar a média residual de óleo saturação e estimar a média da capacidade de troca iônica. ${ }^{104}$

A aplicabilidade dos traçadores em petroquímica pode ser avaliada no artigo de revisão de Ruixiang e colaboradores, ${ }^{105}$ que aborda aspectos históricos, classificação, vantagens e desvantagens dos traçadores químicos, fluorescentes, radioativos e ativáveis, e a utilização destes em petroquímica. ${ }^{105}$ Dentre os tipos de traçadores aplicáveis a reservatórios de petróleo podemos citar: os traçadores químicos - tiocianato, nitrato e álcoois, neste caso alguns mil quilos devem ser injetados para serem detectados $;{ }^{104} \mathrm{o}$ tiocianato de potássio $(\mathrm{KSCN})$ pode ser misturado com álcoois como n-pentanol, isopentanol e n-butanol e aplicado nos reservatórios, o n-butanol apresenta o menor coeficiente de partição com a fase oleosa, o n-pentanol apresenta o maior coeficiente de partição, sendo que o conjunto dos traçadores que apresenta menor absorção pela formação do reservatório é KSCN/n-butanol; ${ }^{106}$ derivados benzênicos com ácidos dicarboxílicos e tricarboxílicos, marcados radioativamente $\left({ }^{14} \mathrm{C}\right.$ ou trítio), os ácidos orgânicos tendem a se decompor em ambientes salinos com temperaturas elevadas, e com o elemento radioativo podem ser detectados em baixas concentrações; ${ }^{107}$ alquildibenzotiofenos; ${ }^{108}$ os gases perfluormetilciclopentano e perfluor-metilciclo-hexano; ${ }^{109}$ os gases $\mathrm{CO}_{2}, \mathrm{CH}_{4}$, $\mathrm{NH}_{3}$ e gases nobres; ${ }^{110}$ ácidos bifenilmonossulfônicos e bifenilpolissulfônicos, ácidos flúor-monosulfônicos e flúor-polisulfônicos, ácidos paraterc-fenilmonossulfônicos e para-terc-fenilpolissulfônicos, ${ }^{111}$ e o ácido nítrico que é empregado no estudo da migração óleo/gás no reservatório de petróleo. ${ }^{112}$ Alguns isótopos ambientais, como o ${ }^{18} \mathrm{O},{ }^{2} \mathrm{He}^{3} \mathrm{H}$ presentes nas moléculas de água, são também utilizados como traçadores ideais, mas existem poucas referências na literatura devido à necessidade de equipamentos mais sofisticados para sua detecção; ${ }^{113}$ entretanto, pode-se citar uma patente recente de King ${ }^{114}$ que utilizou água deuterada $\left(\mathrm{D}_{2} \mathrm{O}\right)$ para estudar as características de um reservatório de petróleo.

É digno de nota a utilização do ácido fluorbenzóico como traçador em petroquímica: Sui e colaboradores ${ }^{115}$ estudaram a aplicabilidade do ácido 2-fluorbenzóico (2-FBA), efetuando uma extração em fase sólida nas amostras de água e posterior análise por cromatografia gasosa acoplada com espectrometria de massas (CG/EM), obtendo um limite detecção para o 2-FBA de $4 \times 10^{-9} \mathrm{~g} / \mathrm{L}$. Um artigo de revisão de Gieles e Beuthan ${ }^{116}$ apresenta resultados promissores do ácido 2-fluorbenzóico como traçador in situ; e uma patente recente de Sui, Li e Zhang ${ }^{117}$ aborda aspectos relacionados ao pré-tratamento, filtragem, medida da fase sólida, combinando a análise por cromatografia gasosa acoplada com espectrometria de massa para a análise de FBAs em reservatório de petróleo.

Cabe aqui destacar que para uso como traçadores petroquímicos, os traçadores fluorescentes geralmente não são utilizados por sofrerem processos de clivagem molecular, ou perda de suas propriedades fluorescentes nas temperaturas geotérmicas dos reservatórios, como já citado. Mas, alguns agentes fluorescentes específicos, tais como xantenos e sulfonatos poliaromáticos que apresentam alta estabilidade térmica, são utilizados em reservatórios geotérmicos. ${ }^{113}$

Dentre os traçadores radioativos, amplamente utilizados nos estudos de reservatórios de petróleo, o trítio na forma de água tritiada é considerado o traçador ideal. ${ }^{85}$ Os traçadores beta ${ }^{14} \mathrm{C} \mathrm{e}{ }^{35} \mathrm{~S}$ são muito utilizados, e poucos radio-traçadores gama têm sido testados, entre eles os complexos hexacianocobaltato - $\mathrm{K}_{3}\left[\mathrm{Co}(\mathrm{CN})_{6}\right]-\operatorname{com}{ }^{57} \mathrm{Co}$ e ${ }^{60} \mathrm{Co}$, e complexos de EDTA com ${ }^{51} \mathrm{Cr} .{ }^{104}$ No caso do ${ }^{35} \mathrm{~S}$ tem-se tempo de meia vida $\left(\mathrm{t}_{1 / 2}\right)$ de 87 dias, é produzido a partir da irradiação do cloreto de potássio $(\mathrm{KCl})$, utilizado na marcação do $\mathrm{SCN}^{-}$no tiocianato de potássio. ${ }^{104} \mathrm{O}$ Co-60 em é um bom traçador, mas a perigosa radiação do Co-60 limita seu uso e está sendo substituído por Co-58, que tem tempo de meia vida $\left(\mathrm{t}_{1 / 2}\right)$ de 67,8 dias. ${ }^{104}$ Vale a pena também destacar que $\mathrm{o}^{131} \mathrm{Ba}$ tem sido utilizado como traçador na indústria de petróleo. ${ }^{118}$

$\mathrm{O}$ uso dos traçadores ativáveis em petroquímica é recente e merece destaque, pois como já citado, não causam danos à saúde e ao ambiente, podem ser obtidos em grandes quantidades com custo relativamente baixo e alta estabilidade, porém há poucas referências na literatura sobre o uso destes traçadores em reservatórios de petróleo. Comumente são estudados os íons lantanídeos e o índio, complexados com ácidos poliaminocarboxílicos como, por exemplo, disprósio, európio e índio complexados com EDTA (ácido etilenodiaminotetracético) e DTPA (ácido etilenodiaminopentacético) utilizados em alguns experimentos como traçador in situ ${ }^{119} \mathrm{Li}$ que patenteou a utilização dos complexos de lantanídeos com derivados do EDTA, ${ }^{120} \mathrm{o}$ ácido hidroxietil-etilenodiaminatriacético (HEDTA), 
tri-Br fosfato (TBP)-EDTA, analisados por ICP-MS. Finalmente, cabe destacar o elemento índio (In) que é um dos mais promissores traçadores ativáveis, pois nos estudos onde este elemento foi complexado com ácido etilenodiaminotetracético (EDTA) e ácido nitracético (NTA) observou-se que a complexação com o EDTA aumenta a solubilidade e a estabilidade do ligante em temperaturas elevadas, quesito importante em altas temperaturas geotérmicas; a absorção do complexo In-EDTA pela formação do reservatório ocorre em temperaturas acima de $200{ }^{\circ} \mathrm{C}$, permitindo assim a análise, pois nesta faixa de temperatura ocorreria a decomposição térmica do ligante. Os resultados experimentais obtidos indicam que os complexos de In-EDTA e In-NTA são excelentes traçadores ativáveis para reservatórios geotérmicos e de petróleo. ${ }^{8}$

\section{CONCLUSÕES}

O interesse científico, tecnológico e comercial pelos traçadores cresceu significativamente nas últimas décadas, devido à expansão do escopo e da aplicabilidade geral destes agentes. Cada vez mais surgem demandas pelo desenvolvimento de novos traçadores e novas metodologias de análise. Desde o uso inicial e específico de traçadores, como agente de monitoramento ambiental de veios aquáticos, atualmente os traçadores são utilizados em quase todos os campos da ciência, tais como medicina, ciências biológicas, química, agricultura, geociências e engenharia, com grande variedade de aplicações tecnológicas e científicas de grande relevância. A importância dos traçadores pode também ser avaliada através dos possíveis impactos diferentes causados pelos resultados obtidos das suas diversas aplicações: impacto científico-acadêmico, como o obtido pelos estudos do metabolismo bioquímico para o desenvolvimento de um novo fármaco e o esclarecimento sobre as cadeias alimentares de ecossistemas diversos; impacto sócio-ambiental, como o obtido pelos estudos da influência antropogênica na contaminação da bioesfera (não só água, mas solos e ar) e, impacto financeiro-industrial de grande atualidade, como o estudo da caracterização e da potencialidade de novos reservatórios de petróleo e da presença de elementos em nível traço em novos materiais de alta tecnologia.

A importância da química merece destaque no contexto geral de traçadores (fluorescentes, radiativos, químicos e ativáveis) devido à necessidade do desenvolvimento de novos agentes traçadores, mais eficientes e menos tóxicos, por parte dos químicos e da colaboração destes no estabelecimento de métodos analíticos modernos e de alta confiabilidade.

\section{AGRADECIMENTOS}

À FAPEMIG (CEX APQ-4911-5.02/07-PPM, PRONEX EDT 479/07), CAPES, CNPq e PETROBRAS pelo auxílio financeiro.

\section{REFERÊNCIAS}

1. Macedo, J. A. B.; Águas \& Águas, 2a ed., CRQ-MG, 2004.

2. Magio, G. E.; Aplicações Industriales De Radiotrazadores Y Fuentes Selladas De Radiación; Proyecto RLA-8-024 (ARCAL, 43), CNEA: Buenos Aires, 2000.

3. Bj rnstad, T.; Maggio, G. E.; Radiotracer technology as applied to interwell communication in oilfields; Manuscript, IAEA: Vienna, 2000; Rossi, P.; Ph. D. Thesis, University of Neuchàtel, 1994.

4. Baena, J. R.; Gallego, M.; Valcarcel, M.; Trends Anal. Chem. 2002, 21, 878.

5. McCurley, J. M.; Radiographics 1995, 15, 1243.

6. Alexander, C. E.; Quinlan, J. F.; Pratical Tracing of Ground Water, with Emphasis on Karts Terranes, Geological Society of América: Cincinnati,Ohio, 1992, vol. 1.
7. Pillary, K. K. S.; Trans. Am. Nucl. Soc. 1976, 23, 102.

8. Chrysikopoulos, C. V.; Kruger P.; Chelated Indium Activable Tracers for Geothermal Reservoirs, SGP-TR-99, Stanford University: Califórnia, 1986.

9. http://www.portalabpg.org.br/PDPetro/3/trabalhos/IBP0192_05.pdf, acessada em Fevereiro 2008.

10. Swarzenski, P. W.; Chem. Rev. 2007, 107, 663.

11. Tuccimei, P.; Salvati, R.; Capelli, G.; Delitala, M. C.; Primavera, P.; Appl. Geochem. 2005, 20, 1831.

12. Treutler, H. C.; Just, G.; Schubert, M.; Weiss. H.; J. Radioanal. Nucl. Chem. 2007, 272, 583.

13. Schubert, M.; Lehmann, K.; Paschke, A.; Sci. Total Environ. 2007, 376, 306.

14. Fan, K.; Han, Y.; Chen, C.; Lin, C.; Lee, C.; Radiat. Measur. 2007, 42, 479.

15. Morelli, D.; Martino, S. D.; Immè, G.; Delfa, S. L.; Nigro, S. L.; Pantanè, G.; Radiat. Measur. 2006, 41, 721.

16. Martens, C. S.; Shay, T. J.; Mendlovitz, H. P.; Matross, D. M.; Saleska, S. R.; Wofsy, S. C.; Woodward, W. S.; Menton, M. C.; Moura, J. M. S.; Crill, P. M.; Moraes, O. L. L.; Lima, R.; Global Change Biol. 2004, 10, 618.

17. Smart, P. L.; NSS Bulletin 1984, 46, 21. (CA 105:158339).

18. Baran, G. R.; Brien, W. J. O.; Tien, T. Y.; J. Dent. Res. 1977, 56, 1323.

19. http://pubs.usgs.gov/twri/twri3-a12/pdf/TWRI_3-A12.pdf, acessada em Fevereiro 2008

20. Chua, L. H. C.; Alexander P. R.; Yee, W. K.; Shuy, E. B.; Edmond, Y. M. Lo.; Lim, T. T.; Tan, S. K.; Ground Water 2007, 45, 85.

21. David, T. H.; Peter, S.; Houghton, P.; Robert, W.; Ted, C.; J. Environ. Eng. 2006, 132, 1664.

22. Harden, H. S.; Chanton, J. P.; Rose, J. B.; John, D. E.; J. Hidrol. 2003, 227, 100 .

23. Corbert, D. R.; Burnett. W. C.; Cable, P. H.; Clark, S. B.; J. Hydrol. 1997, 203, 209.

24. Borsdorf, H.; Roland, U.; Int. J. Environ. Anal. Chem. 2008, 88, 279

25. Goryacheva, I. Y.; Eremin, S. A.; Shutaleva, E. A.; Suchanek, M.; Niessner, R.; Knopp, D.; Anal. Lett. 2007, 40, 1445.

26. Kleimeyer, J. A.; Rose, P. E.; Harris, J. M.; Appl. Spectrosc. 2001, 55, 690.

27. Orth, V. H.; Rehm, M.; Haller, M.; Thiel, M.; Finsterer, U.; Der Anaesthesist 2001, 50, 562

28. Larsen, M.; Acta Ophthalmol Suppl. 1993, 211, 1.

29. Golim, M. A.; Deffune, E.; Ferreira, R. R.; Oliveira, A. P. E.; Padovani, C. R.; Machado, P. E. A.; Rev. Bras. Hematol. Hemoter. 2007, 29, 361.

30. Carlavilla, D.; Moreno, A. M. V.; Fanali, S.; Cifuentes, A.; Electrophoresis 2006, 27, 2551.

31. Adams, E. E.; Stolzenbach, K. D.; Lee, J. J.; Caroli, J.; Funk, D.; Estuar. Coast. Shelf Sci. 1998, 46, 371.

32. Juan, D.; Riyong Huaxue Gongye 2006, 36, 321. (CAN 147:329582).

33. www.connectedwater.gov.au/framework/artificial_tracers.html, acessada em Fevereiro 2008.

34. Rossi, P.; Dorfliger, N.; Kennedy, K.; Muller, L.; Aragno, M.; Hydrol. Earth Syst. Sci. 1998, 2, 101.

35. http://www6.ufrgs.br/bioquimica/posgrad/BTA/hormonios.pdf, acessada em Novembro 2007.

36. Barber, J. A. S.; Parkin, C. S.; Crop Protection 2003, 22, 15.

37. Klauth, P.; Bauer, R.; Ralfs, C.; Ustohal, P.; Vanderborght, J.; Vereecken, H.; Klumpp, E.; Coll. Surf. 2007, 306, 118.

38. Caivola, P.; Taborda, R.; Ferreira, O.; Dias, J. A.; Mar. Geology 1997, 141, 147.

39. Boulenguez, P.; Gestreau, C.; Vinit, S.; Stamegna, J. C.; Kastner, A.; Gauthier, P.; Neurosci. Lett. 2007, 417, 206.

40. Katada, A.; Vos, J. D.; Swelstad, B. B.; Zealear, D. L.; J. Neurosci. Meth. 2006 $155,20$.

41. Gronwall, A.; Ingelman, B.; Nature 1945, 155, 45.

42. Hartmann, S.; Odling, N. E.; West, L. J.; J. Contam. Hydrol. 2007, 94, 315.

43. Brouyere, S.; Dassargues, A.; Hallet, V.; J. Contam. Hydrol. 2004, 72, 135.

44. http://www.histosearch.com/histonet/Oct98A/Re.EvansBlueotherfluoresc. html, acessada em Março 2008. 
45. Thurston, G.; J. Anat. 2002, 200, 575.

46. Murakami, K.; Kondo, T.; Yang, G.; Chen, S. F.; Fujimura, M. Y.; Chan, P. H.; Progr. Neurobiol. 1999, 57, 289.

47. Rákos, G.; Kis, Z.; Nagy, D.; Lur, G.; Farkas, T.; Hortobágyi, T.; Vécsei L, Toldi, J.; Acta Neurobiol. Exp. (Wars) 2007, 67, 149.

48. Schaefer, T.; Geckeis, H.; Bouby, M.; Fanghaenel, T.; Radiochim. Acta. 2004, $92,731$.

49. http://w3.ualg.pt/ Inunes/Artigos/bacteri.pdf, acessada em Dezembro 2007.

50. Kaess.; Tracing Technique in geohydrology, Balkema: Berlin, 1998.

51. Harvey, R. W.; Microbiol. Rev. 1997, 20, 461.

52. Becker, M.; Metge, D. W.; Collins, S. A.; Shapiro, A. M.; Harvey, R. W.; Ground Water 2003, 41, 682.

53. Goldscheider, N.; Haller, L.; Poté, J.; Wildi, W.; Zopfi, J.; Environ. Sci. Technol. 2007, 41, 5252 .

54. Corapcioglu, M. Y.; Vogel, J. R.; Munster, C. L.; Pillari, S. D.; Dowd, S.; Wang, S.; Water, Air, Soil Pollut. 2006, 169, 47.

55. http://en.wikipedia.org/wiki/Radiocontrast, acessada em Fevereiro 2008; SciFinder Scholar ® (www.periodicos.capes.gov.br/portugues/paginaInicial/ novidades/CAS/cas. htm), acessada em Fevereiro 2008.

56. http://www.medonline.com.br/med_ed/med10/contras.htm, acessada em Fevereiro 2008

57. Grenier, N.; Pedersen, M.; Hauger.; Eur. J. Radiol. 2006, 60, 341.

58. Choyke, P. L.; Kobayashi, H.; Abdom. Imaging 2006, 31, 224.

59. Ni, Y.; Hyghe, D.; Verbeke, K.; Witte, P. A.; Nuyts, J.; Mortelmans, L.; Chen, F; Marchal, G.; Verbruggen, A. M.; Bormans, G. M.; Eur. J. Nucl. Med. Molec. Imag. 2006, 33, 595.

60. Nobuyoshi, Y.; Sachi, T.; Gert, P.; Si, W.; Toshitaka, G.; Lam, P. K. S.; Kurunthachalam, K.; Chemosphere 2008, 70, 1247.

61. England, M. H.; Maier, R. E.; Rev. Geophys. 2001, 39, 29.

62. Goddard, R. C. U.; Wilkins, C. S.; Water Res. 1995, 29, 1065.

63. Jerzy, J. B.; Environ. Protect. Eng. 1985, 11, 27.

64. Bhatta, R.; Tajima, K.; Takusari, N.; Higuchi, K.; Enishi, O.; Kurihara, M.; Asian-Australas. J. Anim. Sci. 2007, 20, 1049. (CAN 147:521398).

65. Watson, A. J.; Ledwell, J. R.; J. Geophys. Res. Oceans 2000, 105, 14325.

66. http://www.whoi.edu/science/AOPE/ cofdl/tracerlab/, acessada em Março 2008.

67. Krahn, M. M.; Herman, D. P.; Matkin, C. O.; Durban, J. W.; Lennard, L. B.; Burrows, D. G.; Dahlheim, M. E.; Black, N.; LeDuc, R. G.; Wade, P. R.; Mar. Environ. Res. 2007, 63, 91.

68. Schmidt, H.; Borchardt, G.; Weber, S.; Scherrer, H.; Defect and Diffusion Forum 2007, 263, 219. (CA 148:152369).

69. Alekseev, F. A.; Geologija Nefti (Petroleum Geology) 1958, 2, 1039.

70. Gilland, H. E.; Conley, F. R.; J. Oil Gas 1976, 1, 43.

71. Deicher, M.; Physica B 2007, 389, 51.

72. Nikolic, M.; Nikolic N.; Liang, Y.; Kirkby, E. A.; Romheld, V.; Plant Physiol. 2007, 143, 495.

73. Nariai, T.; Annual Review Shinkei 2006, 1, 52. (CA 146:95718)

74. Perkins, A. C.; Frier, M.; Current Pharm. Des. 2004, 10, 2907.

75. Kairemo, K. J. A.; Tahtinen, M.; Current Pharm. Des. 2004, 10, 2923.

76. Bailey, D. L.; Adamson, K. L.; Current Pharm. Des. 2003, 9, 903.

77. King, M. A.; Pretorius, P. H.; Farncombe, T.; Beekman, F. J.; J. Cell. Biochem. 2002, 39, 221.

78. Bonardi, M.; Groppi, F.; Mainardi, H. S.; Microchem. J. 2002, 73, 153.

79. Chinkes, D. L.; Radioactive tracers: Kirk-Othmer Encyclopedia of Chemical Technology, $5^{\text {th }}$ ed., Seidel, Arza: The University of Texas Medical Branch, Texas, 2006, cap. 21.

80. Ambe, F.; Ambe, S.; Enomoto, S.; Tracer technique: Handbook of Nuclear Chemistry, Bertes, Attila: Kluwer Academic Publishers, 2003, vol. 3.

81. Abreu, B. A L.; Tese de Doutorado, Universidade de São Paulo, Brasil, 2005.

82. Zhang, X. C.; Friedrich, J. M.; Nearing, M. A; Norton L. D.; Soil Sci. Soc. Am. J. 2001, 65, 1508 .

83. Lepoint, G.; Dauby, P.; Gobert, S.; Mar. Pollut. Bull. 2004, 49, 887.
84. Schimel, D. S.; Theory and application of tracers, Academic Press: San Diego, 1993.

85. Waugh, D. W.; Hall, T. M.; Haine, T. W. N.; J. Geophys. Res. Oceans 2003, 108,5 .

86. Ahmad, M.; Tasneem, M. A.; Rafiq, M.; Khan, I. H.; Farooq, M.; Sajjad, M. I.; Appl. Radiat. Isot. 2003, 58, 611.

87. Adar, E.; Nativ, R.; J. Contam. Hydrol. 2003, 65, 19.

88. Koh, D. C.; Plummer, L. N.; Solomon, D. K.; Busenberg, E.; Kim, Y.; Chang, H.; J. Hydrol. 2006, 327, 258.

89. Koh, D. C.; Chang, H. W.; Lee, K. S.; Ko, K. S.; Kim, Y.; Park, W. B.; Hydrol. Proc. 2005, 19, 2225.

90. Hertig, W. A.; Schlosser, P.; Stute, M.; Simpson, H. J.; Ludin, A.; Clark, J. F.; Ground Water 1998, 36, 661.

91. Touratier, F.; Azouzi, L.; Goyet, C.; Tellus B 2007, 59, 318. (CA 148:38819)

92. Vandalen, A.; Wijkstra.; J. Radioanal. Nucl. Chem. 1977, 38, 223.

93. IAEA.; Tracer Techniques In Sediment Transport; Technical Reports Series 145, Vienna, 1973.

94. Llioyd, A.; Parry, S. J.; Lynn, N. M.; Giles, I. S.; J. Radioanal. Nucl. Chem. 2005, 264, 83.

95. Koch, R. C.; Activation analysis handbook, Academic Press: New York, 1960.

96. Sabino, C. V. S.; Neves, M. J.; Menezes, M. A. B. C.; Programa de formação básica em radioquímica, CDTN: Belo Horizonte, 1998, vol.1.

97. Feng, W. Y.; Qian, Q. F.; Ding, W. J.; Chai, Z. F.; J. Radioanal. Nucl. Chem. 2000, 244, 321

98. Liu, P. L.; Tian, J. L.; Zhou, P. H.; Yang, M. Y.; Shi, H.; Soil Till. Res. 2004, $76,147$.

99. Plante, A. F.; Duke, M. J. M.; McGill, W. B.; Soil Sci. Soc. Am. J. 1999, 63, 1284.

100. Jester, W. A.; Trans. Am. Nucl. Soc. 1976, 23, 102.

101. IAEA; Radiotracer Applications in Industry: A Guidebook; Technical Reports Series, n. 423, Vienna, 2004.

102. Burwell, E. L.; J. Oil Gas 1966, 11, 76.

103. Kerrin, S. L.; National Science Foundation, Report NSF/CPE-81015, Washington Dc, 1981.

104. IAEA; Radiotracer Technology As Applied To Industry; IAEA-TECDOC1262, Vienna, 2001.

105. Yu, R.; Zhang, T.; Zhou, W.; Gongye Shuichuli 2007, 27, 12. (CA 149:203864 ).

106. Yang, E.; Chen, C.; Song, K.; Liu, M.; Youtian Huaxue 2007, 24, 12. (CA 148: 541185).

107. Eriksen, D. O.; Bjornstad, V.; Czechoslovak J. Phys. 1999, 49, 861. (CA 131:118164).

108. Wang, T. G.; He, F. J.; Li, M. J.; Hou, Y.; Guo, S. Q.; Chin. Sci. Bull. 2004, 49, 2399.

109. Dugstad, O.; Bjornstad, T.; Hundere, I. A.; J. Petrol. Sci. Eng. 1993, 10, 17.

110. Pruess, K.; Geothermics 2002, 31, 475.

111. Stray; H.; PCT Int. WO 2007148981 2007. (CA 148:102943).

112. Shan, B.; Xinjiang Shiyou Tianranqi 2005, 1, 19. (CA 146:84145).

113. Rose, P. E.; Benoit, W. R.; Kilbourn, P. M.; Geothermics 2001, 30, 617.

114. Anderson, K.; U.S. pat. 2007215385 2007. (CA 147:368144).

115. Sui, Y.; Li, J.; Zhang, P.; Zhipu Xuebao 2004, 25, 155. (CA 141:298230).

116. Gieles, T.; Beuthan, H. C.; Erdol, Erdgas, Kohle, Petrochem. 2004, 120, 26. (CA 140:201950).

117. Sui, Y.; Li, J.; Zhang, P.; Faming Zhuanli Shenqing Gongkai Shuomingshu 20050119 2005. (CA 143:480130).

118. Lun, X.; J. Radioanal. Nucl. Chem. 1988, 124, 97

119. Byegard, J.; Sharnemark, G.; Skalberg, M.; J. Radioanal. Nucl. Chem. 1999, $241,281$.

120. Li, Qun.; Faming Zhuanli Shenqing Gongkai Shuomingshu 200511232005. (CA 145:274462). 